\title{
DIAGNOSTIC FAULT OF THE INDUCTION MACHINE WITH APPLICATION OF THE NEURAL NETWORK
}

\author{
Kheira MENDAZ*, Houria BOUNOUA*, Baghdadi BENAZZA** \\ ${ }^{*}$ Djillali Liabes university, School of Engineering Sciences, IRECOM Laboratory, Electrical Engineering department, \\ Sidi Bel Abbes, 22000, Algeria, e-mail: kheiram76@yahoo.fr \\ ${ }^{* *}$ Djillali Liabes university, School of Engineering Sciences, IRECOM, Electrical Engineering department, \\ Sidi Bel Abbes, 22000, Algeria
}

\begin{abstract}
Although the asynchronous machine is known by its qualities of robustness and low cost of construction, however, it happen that it has an electrical or mechanical fault. This article presented rotoric faults which are treated as part of the detection of broken bars, and the inverter faults (switch fault). This detection technique is based on neural network. The simulation was elaborated on Matlab/Simulink that show results used to assess the performance of the technique presented.
\end{abstract}

Keyword: asynchronous machine, diagnostic, rotoric faults, broken bar, five Levels inverter, neural network.

\section{I NTRODUCTION}

The induction machine is largely used in industry, mainly due to its reliability and relatively low cost. The control of the induction machine must take into account machine specificities: the high order of the model, the nonlinear functioning as well as the coupling between the different variables of control. The new industrial applications necessitate speed variations having high dynamic performances, a good precision in permanent regime, and high capacity of overload on all rang of speed and robustness to the different perturbation.

The voltage source inverters construct a non controllable function in the power electronic; it is used in the variable application domains. The strategy obtaining by this technique is based on the study of variation speed in induction machine. The strong functional evolution was based, on one hand, the development of components for semi-conductor entirely commendable, ability, and robustness, the other hand, on the quasi generalized used of the technique pulse width modulation (PWM) [1] [2].The five levels inverter structural is more adapted in the ground power application, because the output voltage and current presented a reduction of the harmonic distortion.

The diagnostics of electric machines has been widely developed in the industrial world as the intention to obtain a lines production that becomes safe for some applications, necessary. Production lines must be occupied with reliable protection systems because any fault, can lead to damage material or an injury inevitable. To avoid these problems the research, has been working for elabored a diagnostic method. These main have principal objective to prevent the working of the possible risk that can appear at the particular point in the system.

\section{INDUCTION MOTOR ORIENTED MODEL}

An induction machine model can be described by the following state equations in the asynchronous reference frame whose axis $d$ is aligned with the rotor flux vector, can be expressed as: [7] [8]

$$
\begin{aligned}
& \frac{d \Omega}{d t}=\frac{n_{p} L_{m}}{J L_{r}}\left(\Phi_{r d} I_{s q}-\Phi_{r q} I_{s d}\right)-\frac{1}{J} C_{r}-\frac{1}{J} f \Omega \\
& \frac{d I_{s d}}{d t}=-\lambda I_{s d}+\omega_{s} I_{s q}+\frac{K}{\tau_{r}} \Phi_{r d}+n_{p} \Omega K \Phi_{r q}+\frac{1}{\sigma L_{s}} V_{s d} \\
& \frac{d I_{s q}}{d t}=-\omega_{s} I_{s d}-\lambda I_{s q}-n_{p} \Omega K \Phi_{r d}-\frac{K}{\tau_{r}} \Phi_{r q}+\frac{1}{\sigma L_{S}} V_{s q} \\
& \frac{d \Phi_{r d}}{d t}=\frac{L_{m}}{\tau_{r}} I_{s d}-\frac{1}{\tau_{r}} \Phi_{r d}+\left(\omega_{s}-n_{p} \Omega\right) \Phi r q \\
& \frac{d \Phi_{r q}}{d t}=\frac{L_{m}}{\tau_{r}} I_{s q}-\left(\omega_{s}-n_{p} \Omega\right) \Phi_{r d}-\frac{1}{\tau_{r}} \Phi_{r q}
\end{aligned}
$$

With

$\tau_{r}=\frac{L_{r}}{R_{r}}$,

$\sigma=1-\frac{L^{2}{ }_{m}}{L_{s} L_{r}}:$ Scattering coefficient Blondel

$$
\begin{aligned}
& K=\frac{L_{m}}{\sigma L_{s} L_{r}} \\
& \lambda=\frac{1}{\tau_{s} \sigma}+\frac{1}{\tau_{r}}\left(\frac{1-\sigma}{\sigma}\right)
\end{aligned}
$$

\section{ASSOCIATION INDUCTION MACHINE -FIVE LEVELS INVERTER}

The figure (1) represented the principal schematic for one topology of five levels inverter associated with induction machine. 


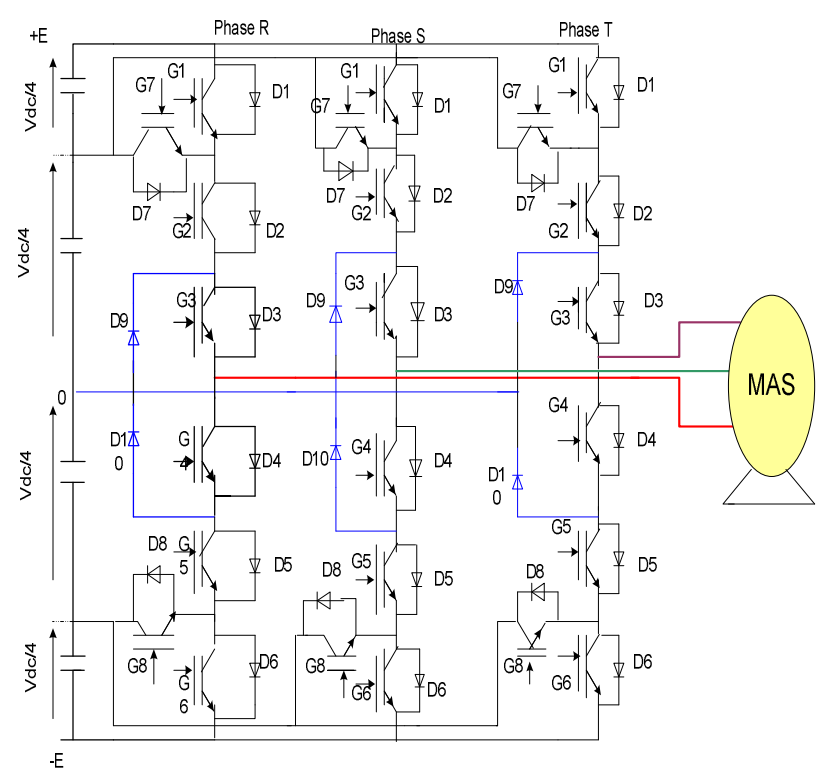

Fig.1 The five levels inverter structural associated with induction machine.

This structure is composed of three symmetrical arms consisted each of six switches in series and two others in parallels $G_{7}$ and $G_{8}$. More two diodes, noted $D_{9}, D_{10}$ permitted to obtaining the zero level for the voltage $V_{k 0}$ $(\mathrm{k}=\mathrm{R}, \mathrm{S}, \mathrm{T})$. Each one of these switches is composed of a two controllable semiconductor and diode appears in teat digs. : [8][10] [11] 12]

In order to avoid short-circuits of the sources voltage, and to have a continuous conduction, there is an operation completely controlled, concerning to adopt a complementary controlled, which is definite as follows:

$$
B_{k 4}=\bar{B}_{k 2}
$$

With

$B_{K S}$ : basic control of the switch $K_{K S}$ of the arm k $(\mathrm{k}=\mathrm{R}, \mathrm{S}, \mathrm{T})$.

$\mathrm{K}_{\mathrm{i}}=1$ : Show the closed of high switch and opened of law switch.

$\mathrm{K}_{\mathrm{i}}=0$ : Show the opened of high switch and closed of law switch

\section{THE ROTORIC FAULT MODELOF THE INDUCTION MACHINE}

It is necessary to developed a model of rotoric fault that explains the disequilibrium who transit a minimum of parameters, these parameters must be the image of the fault presented in the machine [3] [2].

The figure (2) illustrated the conventional modeling of the rotor elementary dipoles with one broken bar.

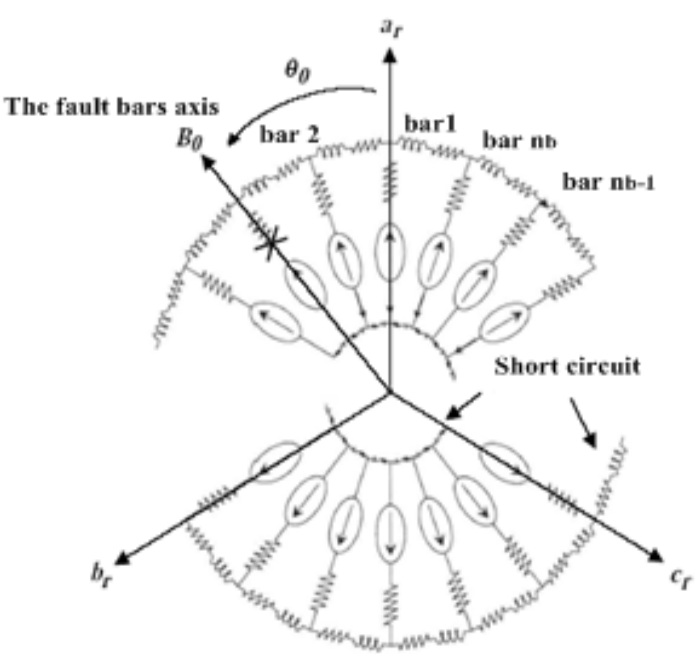

Fig.2 Modelisation of elementary dipoles for rotoric fault

\section{- Modelisation of Broken Bars}

The voltage and flux equations when there are a fault in coil $B_{0}$ can written as:

$0=n_{0} R_{r} \mathrm{I}_{0}+\frac{d \Phi_{0}}{d t}$

$\Phi_{0}=\frac{2}{3} n_{0}^{2} L_{m} \mathrm{I}_{0}+\sqrt{\frac{2}{3}} n_{0} L_{m}\left[\cos \left(\theta_{0}\right) \sin \left(\theta_{0}\right)\right]\left(I_{d q s}+I_{d q r}\right)$

The current in the coil $I_{0}$ represented the fault that was the original stationary magnetic field $H_{0}$ as well as the rotor that oriented on the axis $\theta_{0}$. This magnetic field is the origin of the flux $\Phi_{0}$. We projecting $I_{0}$ and $\Phi_{0}$ on the axis $d$ and $q$ of Park, and we can associated for there the stationary vectors:

$I_{d q_{0}}=\left[\begin{array}{cc}\cos \left(\theta_{0}\right) \\ \sin \left(\theta_{0}\right)\end{array}\right] I_{0}, \Phi_{d q_{0}}=\left[\begin{array}{c}\cos \left(\theta_{0}\right) \\ \sin \left(\theta_{0}\right)\end{array}\right] \Phi_{0}$

The relation (8) and (9) becomes a relation between stationary vector as well as the rotor. The sum machine equations of stator, rotor and coil $B_{0}$ given by this new equations [4] [1] [2] :

$\left[U_{d q s}\right]=R_{s} \mathrm{I}_{d q s}+\frac{d \Phi_{d q s}}{d t}+w p\left(\frac{\pi}{2}\right) \Phi_{d q s}$

$\Phi_{d q s}=L_{f} \mathrm{I}_{d q s}+L_{m}\left(I_{d q s}+I_{d q r}+\sqrt{\frac{2}{3} n_{0}} I_{d q 0}\right)$

$0=\left[R_{r}\right]_{d q r}+\frac{d \Phi_{d q r}}{d t}$

$\Phi_{d q r}=L_{m}\left(I_{d q s}+I_{d q r}\right)+\sqrt{\frac{2}{3}} n_{0} L_{m} I_{d q 0}$ 


$$
\begin{aligned}
& 0=n_{0} R_{r} \mathrm{I}_{d q 0}+\frac{d \Phi_{d q 0}}{d t} \\
& \Phi_{d q 0}=\sqrt{\frac{2}{3}} n_{0} L_{m} \Phi\left(\theta_{0}\right)\left(I_{d q s}+I_{d q r}+\sqrt{\frac{2}{3}} n_{0} I_{d q 0}\right)
\end{aligned}
$$

With:

$$
\Phi\left(\theta_{0}\right)=\left[\begin{array}{cc}
\cos \left(\theta_{0}\right)^{2} & \cos \left(\theta_{0}\right) \sin \left(\theta_{0}\right) \\
\cos \left(\theta_{0}\right) \sin \left(\theta_{0}\right) & \sin \left(\theta_{0}\right)^{2}
\end{array}\right]
$$

Detection fault of broken bars of the induction machine can be obtain by the following equation:

$$
\begin{aligned}
& x^{*}=f(x)+g \cdot u \\
& y=h(x)+H(x) \cdot u
\end{aligned}
$$

With:

$$
\begin{aligned}
& x=\left[\begin{array}{lllll}
I_{d s} & I_{q s} & \Phi_{d r} & \Phi_{q r} & w
\end{array} \theta^{T}, u=\left[\begin{array}{lll}
U_{d s} & U_{q s} & C_{r}
\end{array}\right]^{T}\right. \\
& y=\left[\begin{array}{lll}
I_{d s} & I_{q s} & w
\end{array}\right]^{T}
\end{aligned}
$$$$
f(x)=\left[\begin{array}{c}
-\left(\left(R_{s} I+R_{e q}\right) L_{f}^{-1}+w p\left(\frac{\pi}{2}\right)\right) I_{d q s}+\left(R_{e q} L_{m}^{-1}-w p\left(\frac{\pi}{2}\right)\right) L_{f}^{-1} \Phi_{d q r} \\
R_{e q} I_{d q s}-R_{e q} L_{m}^{-1} \Phi_{d q r} \\
\frac{p^{2}}{2}\left(I_{q s} \Phi_{d r}-I_{d s} \Phi_{q r}\right)-\frac{f_{r}}{J} w
\end{array}\right]
$$$$
g=\left[\begin{array}{ccc}
\frac{1}{L_{f}} & 0 & 0 \\
0 & \frac{1}{L_{f}} & 0 \\
0 & 0 & 0 \\
0 & 0 & 0 \\
0 & 0 & -\frac{p}{J} \\
0 & 0 & 0
\end{array}\right]
$$

$$
h(x)=\left[\begin{array}{c}
I_{d s} \\
I_{q s} \\
w
\end{array}\right] \begin{aligned}
& R_{e q}=R_{r}\left(1-\frac{\alpha}{1+\alpha} \Phi\left(\theta_{0}\right)\right) \\
& \text { where } \\
& \alpha=\frac{2}{3} n_{0}
\end{aligned}
$$

\section{DIAGNOSTICS FAULTS OF FIVE LEVELS INVERTER}

In the inverter five levels, the phases voltage have fifteen levels under symmetrical functional, but their voltage levels seem to be different with each fault commutation. The phase voltage for the positive period has only five levels because the phase current transits the switch $\mathrm{K}_{17}$ replacing the switch $\mathrm{k}_{11}$ in the positive state (P). In the event of commutation fault of switch $\mathrm{k}_{12}$, the phase voltage for the positive period has only three levels because the phase current transits the switch $\mathrm{K}_{13}$ in the positive state. Consequently when each commutation fault occurs, the fictitious phase voltage was differently between them. [9] [12]

The fault of $\mathrm{K}_{17}$ and $\mathrm{K}_{12}$ induces a disequilibrium in the three phases, which translates by the discharge of the lower condensers of the arm $\mathrm{R}$ for the five levels inverter. [2] [3] [5] [10]

$\mathrm{K}_{12}$ : the switch of first arm (phase $\mathrm{R}$ ) composed for $\left[G_{2}, D_{2}\right]$

$\mathrm{K}_{11}$ : the switch of first arm (phase R) composed for $\left[G_{1}, D_{1}\right]$

$\mathrm{K}_{13}$ : the switch of first arm (phase $\mathrm{R}$ ) composed for $\left[G_{3}, D_{3}\right]$

$\mathrm{K}_{17}$ : the switch of first arm (phase $\mathrm{R}$ ) composed for $\left[G_{7}, G_{7}\right]$

\section{CONSTRUCTION OF NEURAL NETWORK}

Supervise techniques for neural networks are based on the existence of a database of training data, from which one seeks to find a relationship between the input variables and output variables. From these input variables, the neural network provides a response characterized by two types of output variables.

Actual output variables which can represent an estimate of the supervise parameter or output categorical variables that represent the state of functionality equipment.

The type of neural networks application in the supervise domains are related to the nature of the output data.

Determining the neural model for the identification is an essential phase which may be more or heavy months for executed the industrial diagnosis.

The algorithm allows us to select the robust neural model, for identification will be aspire in the following steps:

a. The knowledge about the system to be identified.

b. Choisen of the inputs and outputs of the neural model.

c. Determination of the internal behavior of the number of neurons in each hidden layer).

d. Choisen of activation functions.

e. Choisen of accuracy and the number of iteration.

In this neural network (RNA) we used the variables \{ the electromagnetic torque $\left(\mathrm{C}_{\mathrm{e}}\right)$ and the rotation speed $\left.\left(\mathrm{w}_{\mathrm{r}}\right)\right\}$ which are used because they are more representative of the fault (their paces varied considerably in the event of application of a fault). [5] [6]

On the other hand, their measurements are available by sensors which provide physical size.

The neural network diagnosis was the diagnosis external method, it uses the automatic classification of the signals and formes. 
The structural multi layer perceptron used in the neural network of the asynchronous machine is given in Figure (3):

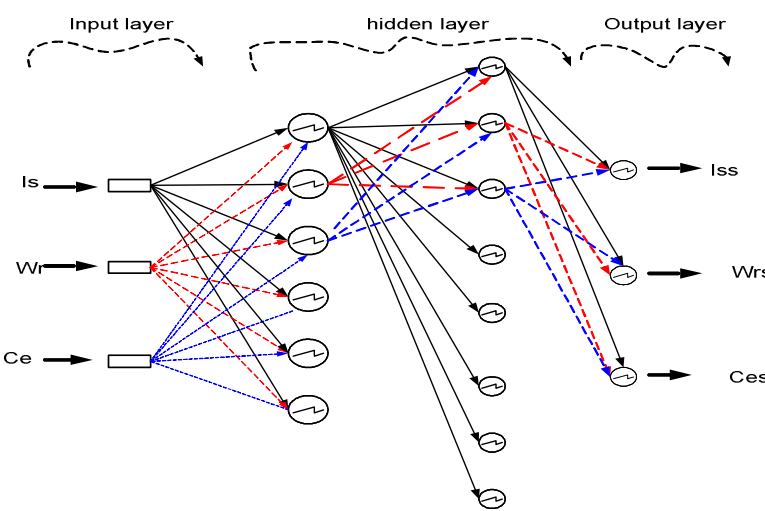

Fig. 3 Multilayer perceptron, structural $(2,3,1)$.

The Figure (4) illustrated the application of neural network model for the induction machine.

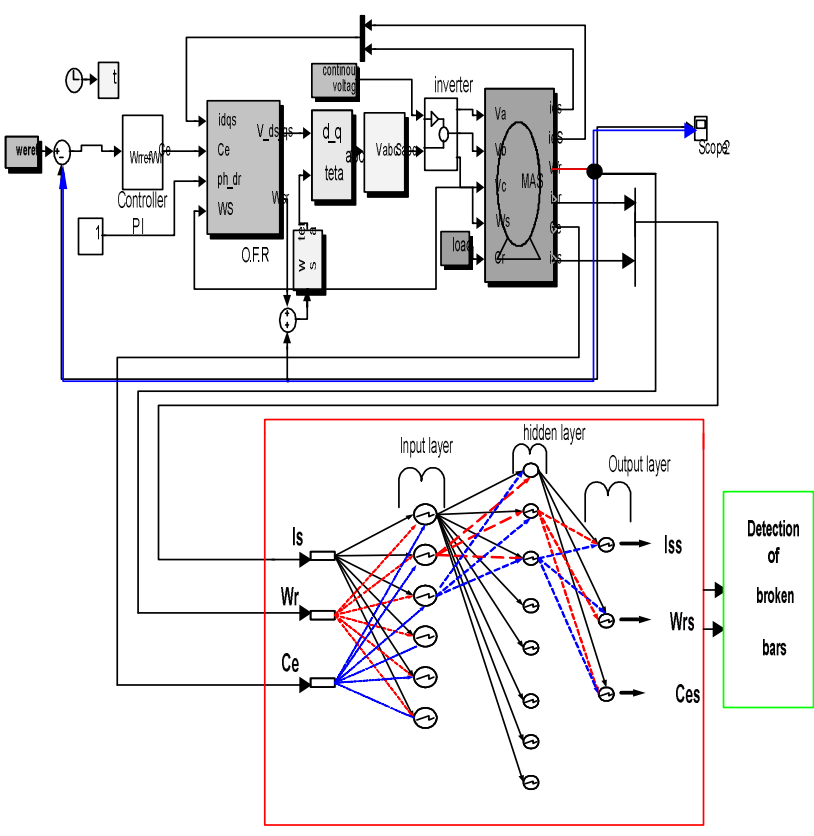

Fig.4 Command of induction machine with application neural network model.

$C_{s}$ : Input electromagnetique torque of neural network.

$W_{r}$ : Input measured speed of neural network.

$I_{s}\left(I_{s a}, \boldsymbol{I}_{\mathrm{rc}}\right)$ : Input statoric, rotoric current of neural network.

The mathematical model of neural given by the following equation :

$y=\sum_{i=1}^{n} w_{i} x_{i}+b$ $y$ : Output neural, $\left(x_{1}, x_{2}, \ldots \ldots, x_{n}\right)$ are the inputs neural, ( $\left.w_{1}, w_{2}, \ldots \ldots, w_{n}\right)$ the correspondence heaviness and $b$ is bias of neuron.

After the upload of the output and input, we created a neural network of three layer (six input layer, three output layer and height hidden layer), by the utilization of Matlab"newff" function, and the chosening of learning function"trainlm".

However if the neural network is constructed and the learning afflicted the satisfactory performances, we utilized the Matlab function "train" and simulated the results (utilization of Matlab function "sim").

In our model of induction machine, the speed $\mathrm{W}_{\mathrm{r}}$ ' electromagnetique torque $\mathrm{C}_{\mathrm{e}}$ and the statoric, rotoric current $\left(I_{s}, I_{\mathrm{ra}}\right)$ are the input of neural network, and the $\left(C_{\oplus g}, I_{s g}, W_{r s}\right)$ are the outputs of neural network which designated the value $\left(\begin{array}{llll}0 & 0 & 1 & 0\end{array}\right)$, so the correspondent fault: broken bars.

0 : there is not a fault.

1 : induces of fault

$C_{\oplus g,} I_{g g}, W_{r g:}$ give the time of fault and the number of broken bars.

The neural network can detect the fault time of broken bar, if we have a broken bar at $\mathrm{t}=2 \mathrm{~s}$, the neural network accurately this time of broken bar and facilitates to show the existence of this fault.

The figure (5) shows the existence of broken bar time at $t$ $=2 \mathrm{~s}$.

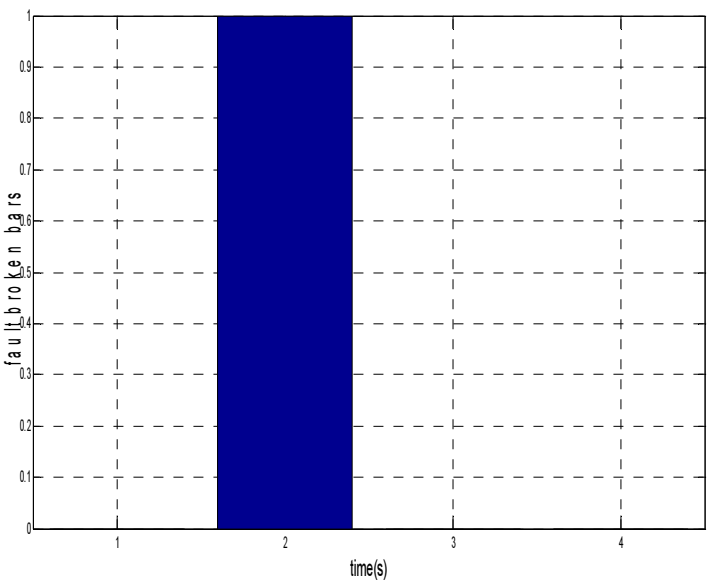

Fig. 5 Dection of broken bars at $t=2 s$

The figure (6) shows with the application of the neural network that there are faults of broken bars (four broken bars) in induction machine but with different time:

$\mathrm{t}=1 \mathrm{~s}$ first broken bar

$\mathrm{t}=2 \mathrm{~s}$ second broken bar

$\mathrm{t}=3 \mathrm{~s}$ the third broken bar

$\mathrm{t}=4 \mathrm{~s}$ fourth broken bar

finally, the neuron networks helped us to know the time of fault (broken bar) and the number of broken bar. 


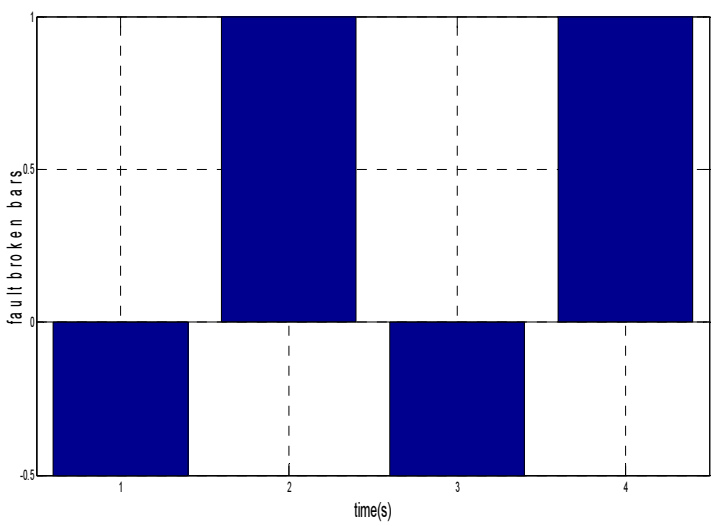

Fig. 6 Dection of broken bars at $\mathrm{t}=1 \mathrm{~s}, \mathrm{t}=2 \mathrm{~s}$, $\mathrm{t}=3 \mathrm{~s}$ and $\mathrm{t}=4 \mathrm{~s}$

\section{SIMULATION RESULTS}

The simulation was elaborated on Matlab/Simulink for the induction machine associated with five levels inverter. For showing the effect of broken bars on induction machine with utilization of neural network (show the effect of the broken bars on simulated vectors: speed $\left(\mathrm{W}_{\mathrm{r}}\right)$, electromagnetic torque $\left(\mathrm{C}_{\mathrm{e}}\right)$ and the statoric and rotoric current $I_{\mathrm{sa}}, I_{\mathrm{ra}}$ ), and the effect of switching fault for the inverter on the simulated vector for the induction machine.

- Bars fault.

The type of fault that we study is the broken bars of the cage asynchronous machine.

Utilization of neural network for the detection of broken bars gives the following results.

Figures (7) and (8) represent the characteristics of the sound machine. The load torque of $10 \mathrm{Nm}$ is applied at $\mathrm{t}=$ $(0.5 \mathrm{~s}, 1 \mathrm{~s})$.

The figure (9) and (10) represent the characteristics of the induction machine with one broken bar at $\mathrm{t}=1.5 \mathrm{~s}$ and two broken bar at $\mathrm{T}=2 \mathrm{~s}$.

The analysis of the electromagnetic torque (Fig. 9) shows a significant change in its appearance when rotor faults occur. The presence of an oscillation, when there is a rotoric fault of the machine, is due to the consideration of space harmonics in the model.

We observe a slight modulation disturbs the evolution of torque when the first bar is broken at $t=1.5 \mathrm{~s}$. We also note that this modulation becomes more important with the advent of second fault at $t=2 \mathrm{~s}$. In theory, this amplitude modulation is identical to the speed frequency $2 \mathrm{gf}$ but as we can see, it is relatively difficult to discern with a simple visual analysis. We note that the first broken bar indicates a very small increase in the current flowing through the rotor (Figure 10).

- Inverter fault.

From the five levels inverter, the voltage and the currents $\mathrm{I}_{\mathrm{sa}}, \mathrm{I}_{\mathrm{ra}}$ resulting from the faults of the switches $\mathrm{K}_{17}$ illustrated by the figure (10) and the figure (13), that notice how the faults of this switcher $\mathrm{K}_{17}$ induces an disequilibrium on these currents and voltage.

The figure (11) represented the lead of induction machine before and during the fault, which are translated by an increasement of speed and oscillations of the torque. After this fault we have a decreasement of speed.

If they have a production of the fault in the five levels inverter, the current deporting in the medium point caused a ground effect in the charge/discharges condensers variation. The fault in high switchers, produce an increasement in lower discharges condensers, and the voltage level appear to be different for each switching fault, this disadvantage of five levels inverter have an influence on the induction machine.

\section{- Bars fault with application of load torque.}

The figures $(14,15)$ show the evolution of the speed, the electromagnetic torque and statoric, rotoric current in the test of broken bars (one broken bar at $\mathrm{t}=1 \mathrm{~s}$ and two broken bars at $\mathrm{t}=2 \mathrm{~s}$ ).

- During motor startup.

- From the moment $\mathrm{t}=0.5 \mathrm{~s}$ the nominal load torque is applied.

-At $\mathrm{t}=1 \mathrm{~s}$ the first bar is broken and at $\mathrm{t}=2 \mathrm{~s}$ the second bars is broken, so the default is caused, noting us:

- The deterioration of the bar reduces the average value of the electromagnetic torque and brings up the oscillation of torque is the rotational speed.

- Undulation of current amplitude appears with the broken bar.

- It is remark that the increase in number of broken bar causes increase in the amplitude of the fluctuations speed, and electromagnetic torque, which causes the deterioration of the machine enrolment.

- The amplitude of the stator phase currents is proportional to the number of broken bars.

- The currents in the broken bars falling practical to zero, but the currents in the neighboring bars become disequilibrium, the currents through the broken bars then divided into the neighboring bars.

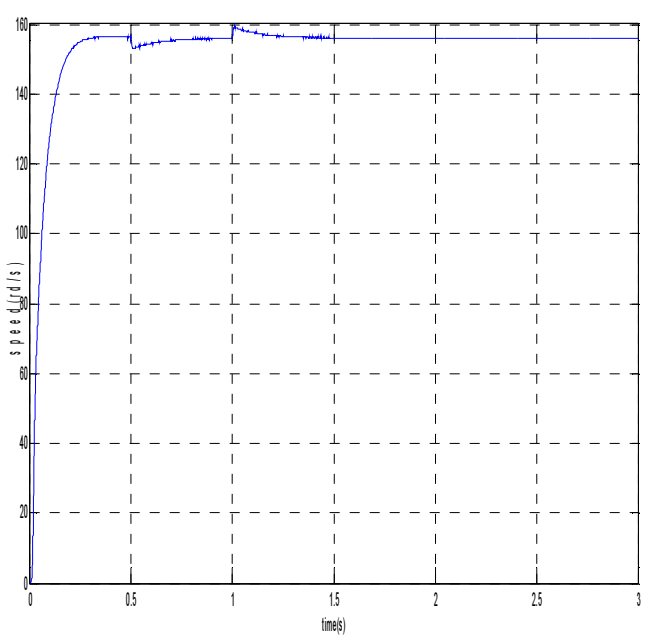




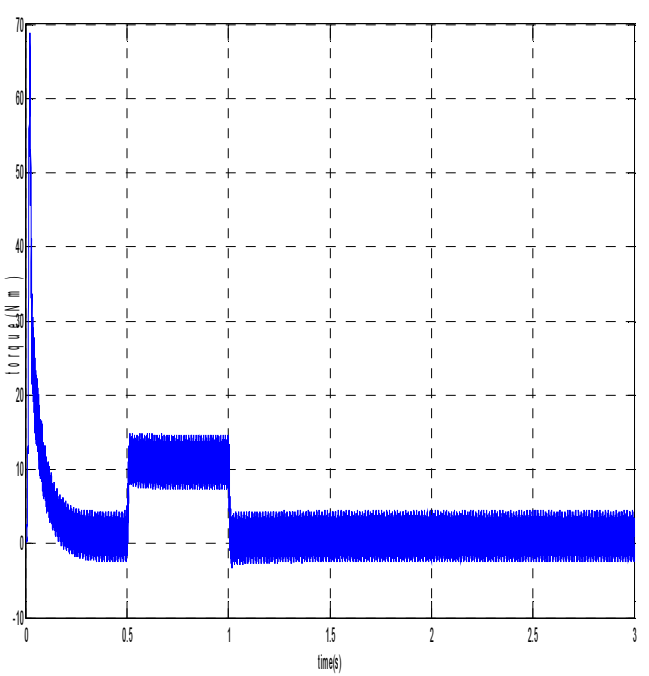

Fig. 7 Speed and electromagnetic torque result of induction machine without fault with application of load torque $\mathrm{Cr}$ at $\mathrm{t}=$ $(0.5 \mathrm{~s}, 1 \mathrm{~s})$.
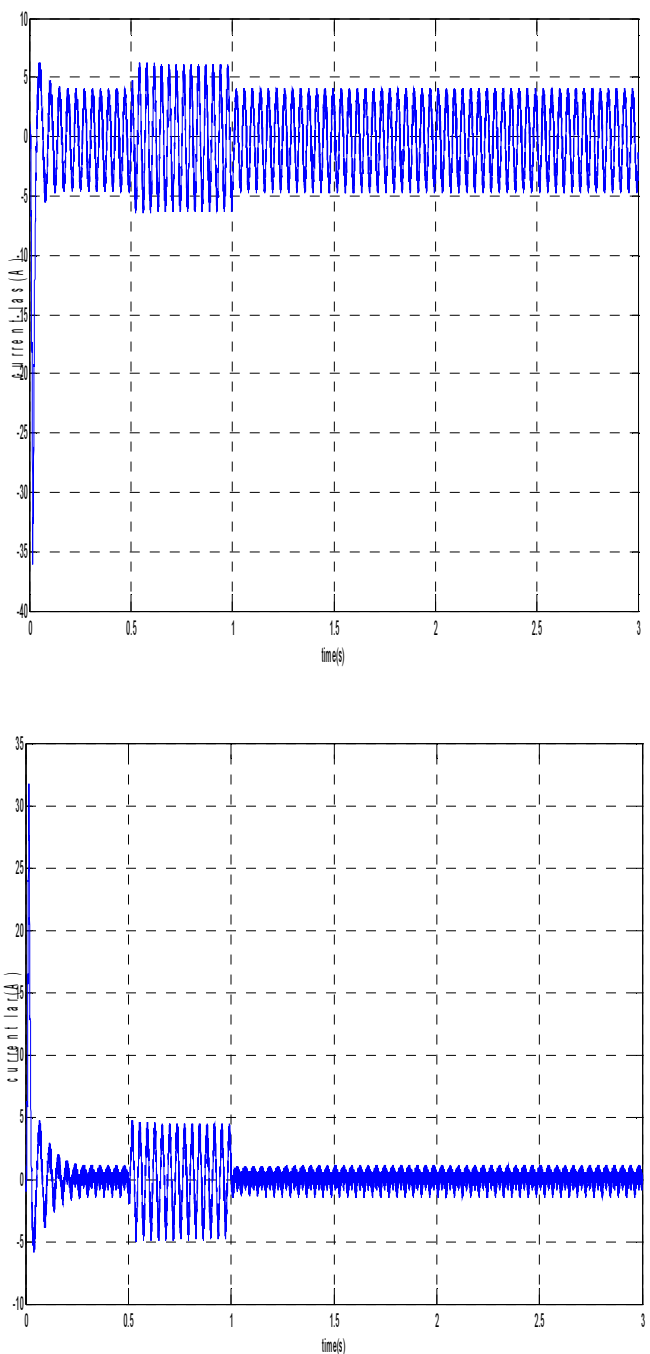

Fig.8 The current $I_{\text {sa }}, I_{r a}$ result of induction machine without fault with application of load torque $\mathrm{Cr}$ at $\mathrm{t}=(0.5 \mathrm{~s}, 1 \mathrm{~s})$.
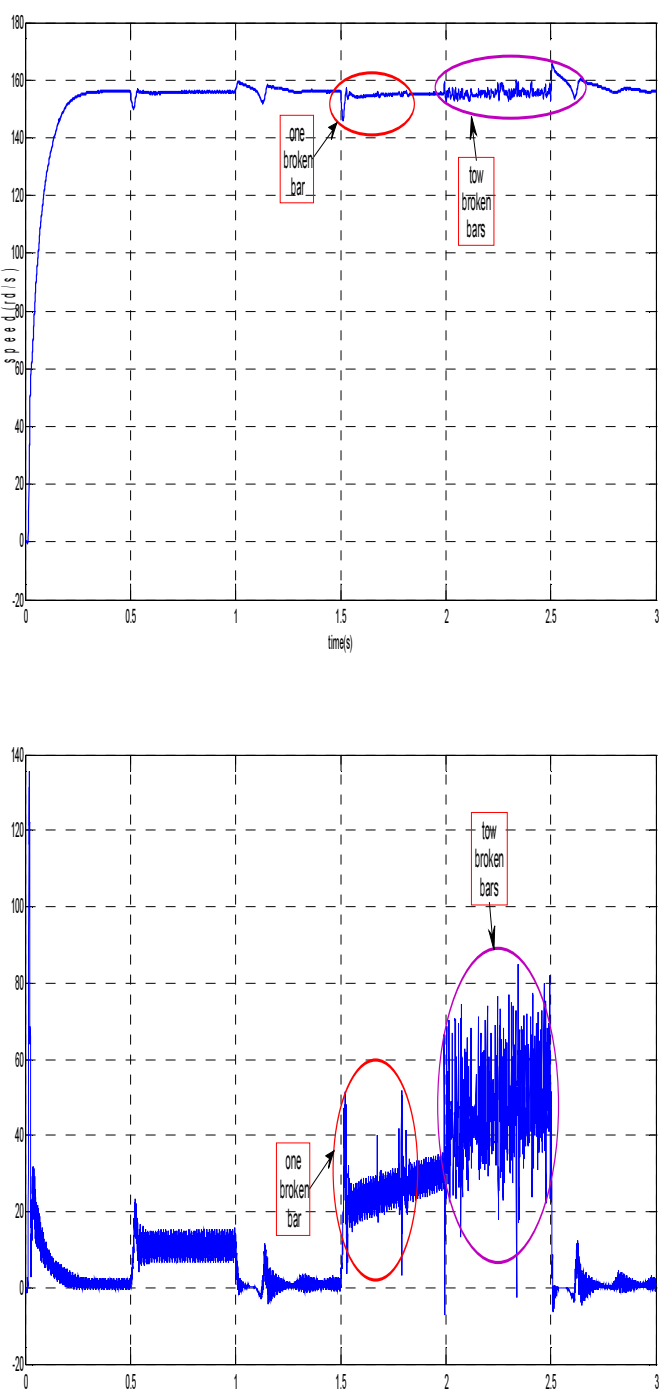

Fig. 9 Speed and electromagnetic torque result of induction machine with one broken bar at $\mathrm{t}=1.5 \mathrm{~s}$ and tow broken bars at $\mathrm{t}=2 \mathrm{~s}$ with application of load torque $\mathrm{Cr}$ at $\mathrm{t}=(0.5 \mathrm{~s}, 1 \mathrm{~s})$.

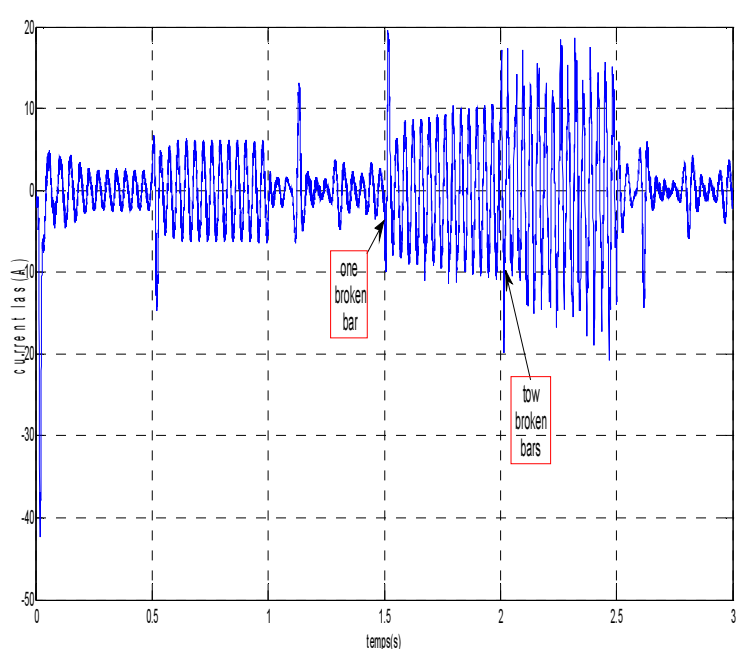




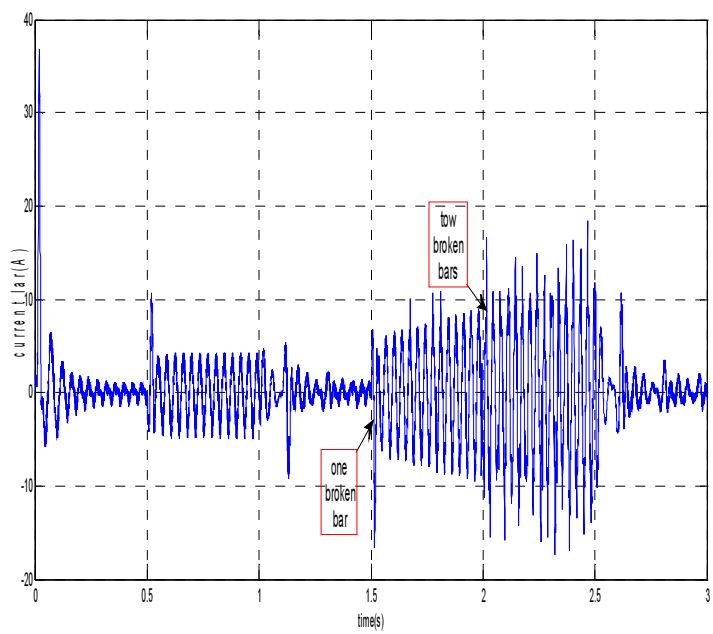

Fig. 10 The current $I_{\mathrm{sa}}, I_{\mathrm{ra}}$ result of induction machine with one broken bar at $\mathrm{t}=1.5 \mathrm{~s}$ and tow broken bars at $\mathrm{t}=2 \mathrm{~s}$ with application of load torque $\mathrm{Cr}$ at $\mathrm{t}=(0.5 \mathrm{~s}, 1 \mathrm{~s})$.

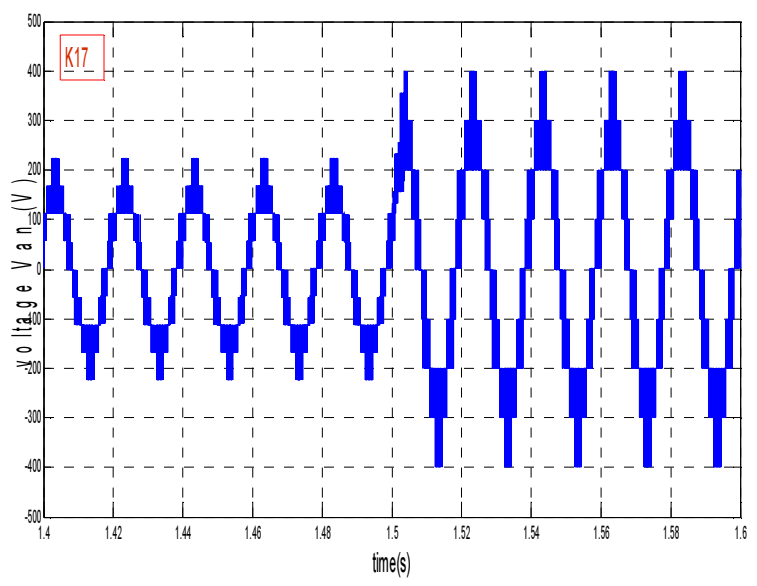

Fig.11 The voltage results $V_{\text {an }}$ of five levels inverter with fault of switch $\mathrm{K}_{17}$ at $(1,1.5) \mathrm{s}$

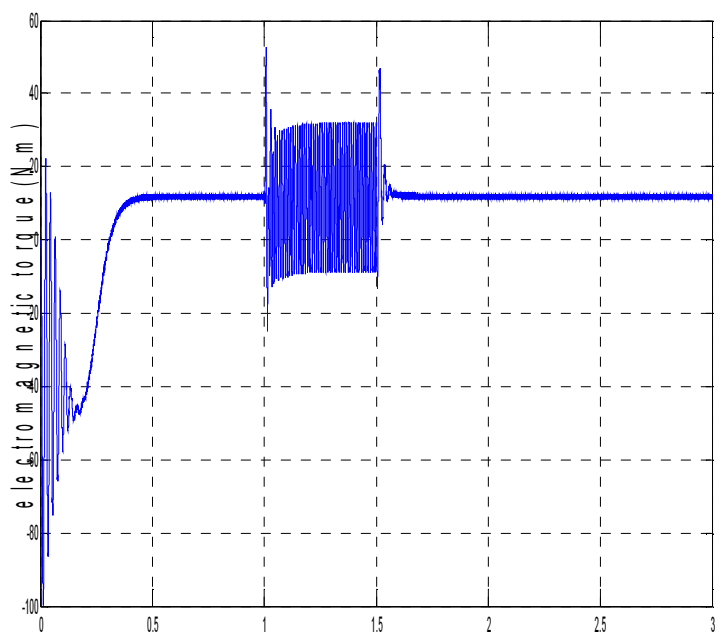

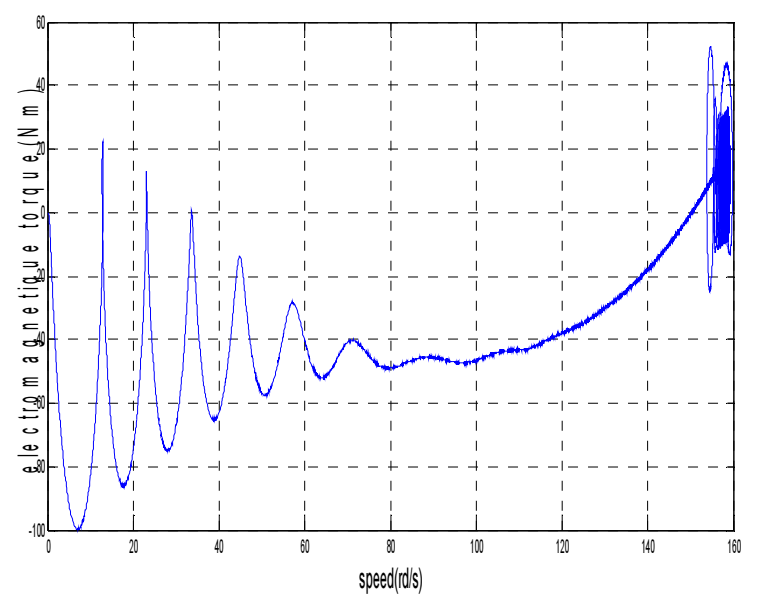

Fig. 12 Speed, electromagnetic torque and speed=t (torque) results of induction machine with fault in switch of five levels inverter $\mathrm{K}_{17}$ at $\mathrm{t}(1,1.5) \mathrm{s}$
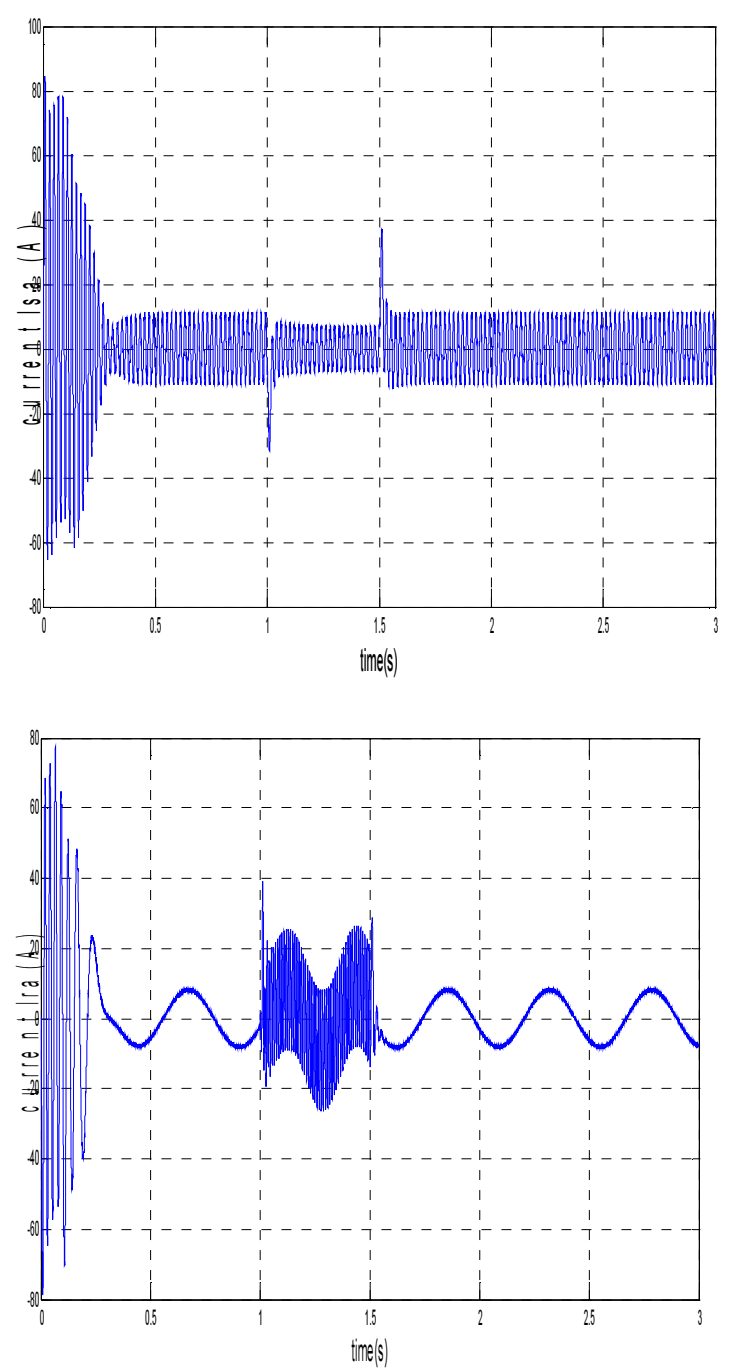

Fig. 13 The current $I_{\text {sa }}$, $I_{\text {ra }}$ result of induction machine with fault in switch of five levels inverter $\mathrm{K}_{17}$ at $\mathrm{t}(1,1.5) \mathrm{s}$ 

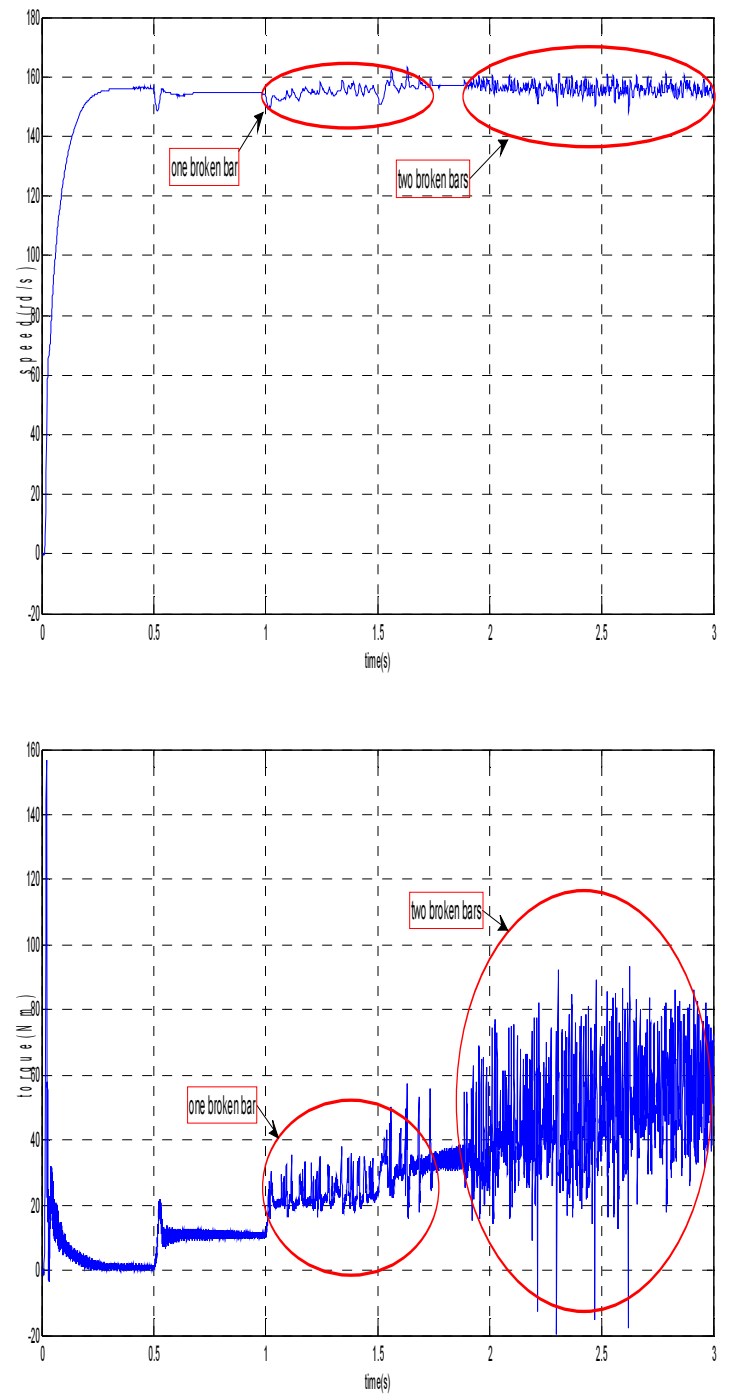

Fig. 14 Speed and electromagnetic torque result of induction machine with one broken bar at $\mathrm{t}=1 \mathrm{~s}$ and tow broken bars at $\mathrm{t}=2 \mathrm{~s}$ with application of load torque $\mathrm{Cr}$ at $\mathrm{t}=0.5 \mathrm{~s}$

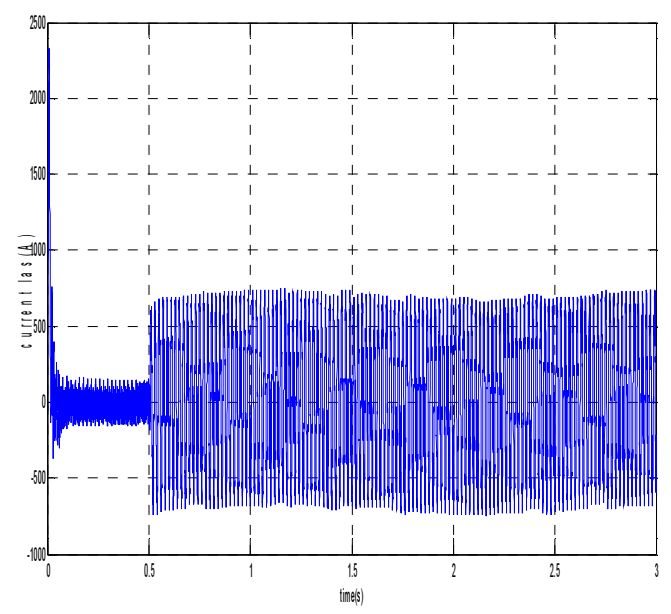

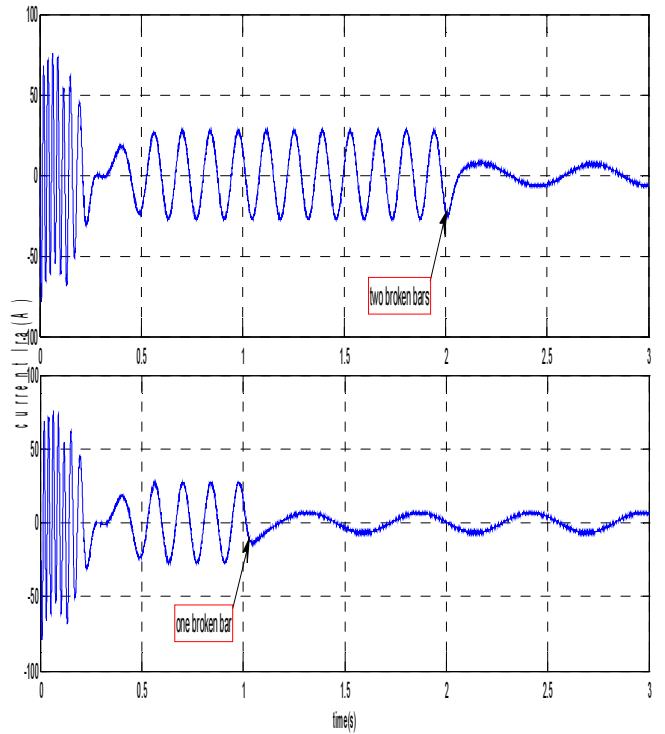

Fig. 15 The current $I_{s a}, I_{r a}$ result of induction machine with one broken bar at $\mathrm{t}=1 \mathrm{~s}$ and tow broken bars at $\mathrm{t}=2 \mathrm{~s}$ with application of load torque $\mathrm{Cr}$ at $\mathrm{t}=0.5 \mathrm{~s}$

\section{CONCLUSIONS}

In this work, we have shown the effect of the broken bar rotoric with a consideration of space harmonics, and so the most significant identified signatures in the spectrum of the stator current from the results obtained by the simulation.

The broken bars create:

- Oscillations on the torque and speed.

- The increase in amplitude of the average couple.

Concerning the five levels inverter fault, note that as fault occur, the current flowing in the medium point land a ground effect in the variation of charge / discharge condensers.

As the fault occurs, a disequilibrium voltage produced between the high and lower condensers. Since the disequilibrium voltage increases the blockage transit each device commutation and caused a serious problem for the protection of system.

\section{REFERENCES}

[1] BACHIR, S. - TNANI, S. - CHAMPENOIS, G. SAINT-MICHEL, J. : Modélisation et diagnostic des ruptures de barres rotoriques par identification paramétrique, Electrotechnique du Futur'01, Nancy, France, pp. 165-170, Nov. 2001.

[2] DIDIER, G. - RAZIK, H.: La détection d'un défaut au rotor des moteurs asynchrones, Revue EI, $\mathrm{N}^{\mathrm{O}} .27$, Dec. 2001. 
[3] RAISON, B.: Détection et localisation de défaillances sur un entrainement électrique, Thèse de doctorat, Institut National Polytechnique de Grenoble, France, 2000.

[4] GAETAN, D.: Modélisation et diagnostic de la machine asynchrone en présence de défaillance, Thèse de doctorat, Oct. 2004, Nancy I.

[5] HAMMOUMI, A. - MASSOUM, A. MEROUFEL, A. - WIRA, P.: Application de réseaux de neurons pour la machine asynchrone sans capteur mécanique, Acta Electrotechnica, pp. 99104, volume 53, $\mathrm{N}^{0} 2,2012$.

[6] MEROUFEL, A. - DJERIR, Y. - MASSOUM, A. HAMMOUMI, A. : Commande vectorielle par les réseaux de neurones artificiels de l'énergie d'une MADA intégrée à un système éolien, Revue des Energies Renouvelables, pp. $669-682$, Vol. $13 \mathrm{~N}^{\circ} 4$, 2010.

[7] MENDAZ, K. : Développement de nouvelle méthodes numérique pour l'analyse dans la conversion des systèmes électromagnétiques de grande capacité, Mémoire de magister ; université de Sidi Bel Abbes 2008.

[8] MEDOUED, A. : Surveillance et diagnostic des défauts des machines électriques : applications aux moteurs asynchrones, thèse de doctorat, Université du 20 Août 1955-Skikda, 2012.

[9] SEGUIER, G. - LABRIQUE, F. : Les convertisseurs de l'électronique de puissance, volume 04, technique et documentation-Lavoisier, 1989.

[10] OUHID, B. : La contribution de l'analyse des onduleurs multi niveaux, mémoire de magister, 2005.

[11] MENDAZ, K. - BOUNOUA, H. - FELLITI, M. : Diagnostic of inverter three Levels Associated with
Asynchronous Machine, International Journal of Engineering Research and Technology IJERT, Vol. 2, Issue 9, Sep. 2013.

[12] MENDAZ, K. - BOUNOUA, H. - FELLITI, M. : Comparative Study of Diagnostic of inverter three and five Levels Associated with Asynchronous Machine, International Journal of Science and Research (IJSR), Vol. 2, Issue 9, Sep. 2013.

Received February 25, 2014, accepted March 16, 2014

\section{BIOGRAPHIES}

Kheira Mendaz was born in Ain Témouchent, Algeria, in 1976. He received the engineer in electrical engineering from Djillali Liabes University, Sidi Bel Abes, Algeria, in 2005, and the M.S degrees in electrical engineering from Sidi Bel Abbes University, Algeria, in 2008; His research interests include high-frequency power conversion, magnetic design, EMI reduction techniques, power electronics and EMC in power converter.

Houria Bounoua received the B.S degree in electrical engineering from USTO (Technology Sciences University of Oran), Algeria in 1983, the M.S. and Ph.D degrees in electrical engineering from Sidi Bel Abbes University, Algeria, in 1991 and 2004, respectively. Since 1983, she is a teaching member and involves in research on Numerical command on Power Systems, at Sidi Bel Abbes University (Algeria).

Baghdadi Benazza He received the engineer in electrical engineering from Djillali Liabes University, Sidi Bel Abes, Algeria, in 1995, and the M.S degrees in electrical engineering from Sidi Bel Abbes University, Algeria, in 2008. His research interests include high-frequency power conversion, magnetic design, EMI reduction techniques, power electronics and EMC in power converter. 